\title{
Functional significance of nerve growth factor and its receptor (TrkA) in inflammatory arthritis
}

\author{
Smriti K Raychaudhuri and Siba P Raychaudhuri* \\ See related research by Barthel et al., http://arthritis-research.com/content/11/3/R82
}

We read the article by Barthel and colleagues [1] in this issue of Arthritis Research \& Therapy with great interest. They reported that neurotrophin receptors/ligands and specifically nerve growth factor (NGF) and NGF receptor (NGF-R) (TrkA and p75) are expressed in synovial fluid (SF) cells and synovial tissue (ST) of patients with rheumatoid arthritis (RA) or spondyloarthritis (SpA). The authors also looked for the cellular source of NGF and demonstrated that the $\mathrm{T}$ cells and monocytes/macrophages derived from SF of patients with RA/SpA are enriched with NGF. Furthermore, they reported that STderived fibroblast-like synoviocytes (FLSs) did not produce NGF in vitro. In a recent publication, we observed similarly that NGF levels in SF were significantly higher in patients with psoriatic arthritis (PsA) $(365.5 \pm 85.2 \mathrm{pg} /$ $\mathrm{mL})$ or RA $(120 \pm 35 \mathrm{pg} / \mathrm{mL})$ than in patients with osteoarthritis (OA) (30 $\pm 6 \mathrm{pg} / \mathrm{mL})$ [2]. However, in regard to the source of NGF, we observed that FLSs produced a significant amount of NGF. Here, we would like to share our observations about the NGF/TrkA system in human FLSs and its function.

Synovial biopsies from patients with meniscal injury without any other joint diseases or PsA, OA, or RA were collected. FLSs were isolated and examined for NGF/ NGF-R expression in accordance with our standardized protocols [2]. Using a highly sensitive enzyme-linked immunosorbent assay (ELISA) for human NGF (NGFEmax assay; Promega Corporation, Madison, WI, USA) and Hi-D fluorescence-activated cell sorting analyses, we observed that under basal conditions FLSs from healthy individuals express low levels of NGF/TrkA. However, there was a marked upregulation of NGF and TrkA in these FLSs following stimulation with tumor necrosis factor-alpha and interleukin-1-beta (Table 1). A critical observation was that FLSs from patients with PsA

*Correspondence: sraychaudhuri@ucdavis.edu

VA Medical Center Sacramento and University of California-Davis School of Medicine, Department of Medicine-Division of Rheumatology, Allergy and Clinical Immunology, 1911 Geneva Place, Davis, CA 95618, USA or RA produced spontaneously higher levels of NGF and had increased expression of TrkA compared with FLSs of patients with OA (Table 1). Furthermore, we observed that NGF significantly stimulated the proliferation of FLSs derived from PsA synovial tissue (Figure 1). Barthel and colleagues [1] cultured FLSs from only one patient with RA and one patient with SpA and noticed that FLSs did not produce NGF, but the authors do mention that they can't rule out the production of NGF by FLS. We cultured FLSs from 15 subjects (Table 1), and it is also possible that the NGF ELISA kit that we used is more sensitive.

A fully formed pannus is characterized by proliferation of FLSs, inflammatory infiltrates, and a marked angiogenesis. NGF and its receptor system are known to

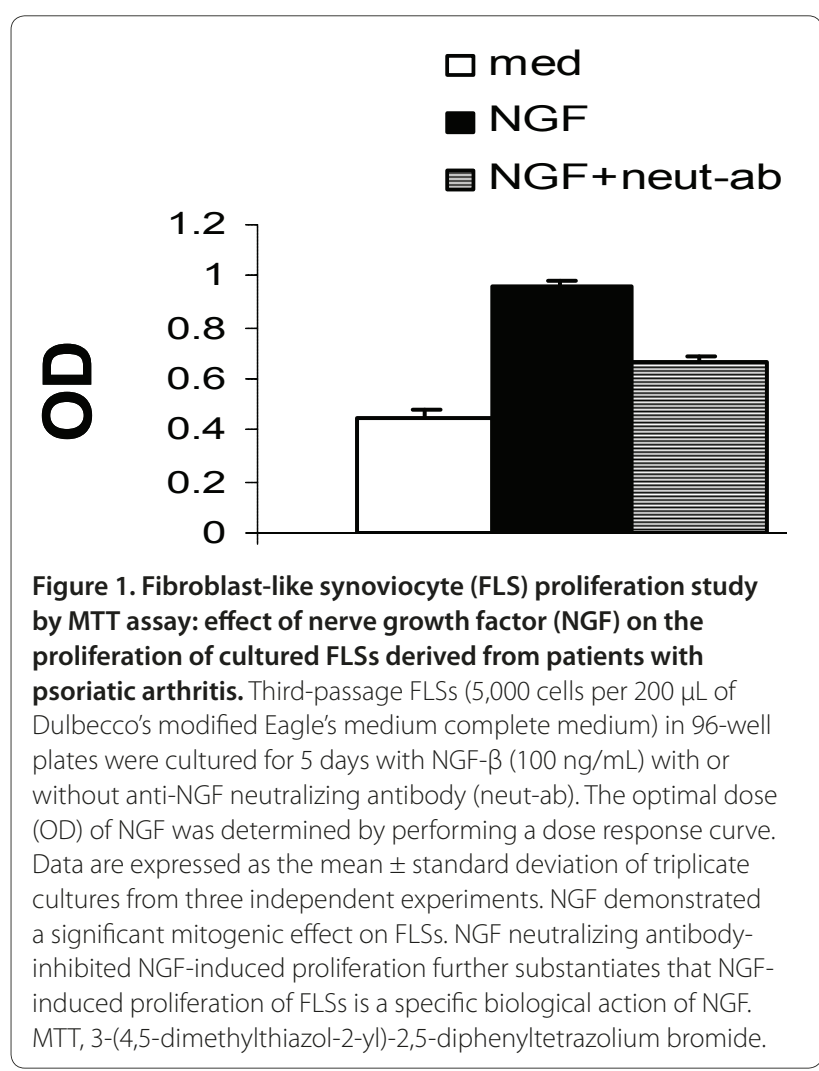


Table 1. Unstimulated fibroblast-like synoviocytes of patients with psoriatic arthritis or rheumatoid arthritis express higher levels of nerve growth factor and TrkA

\begin{tabular}{|c|c|c|c|c|}
\hline \multirow[b]{2}{*}{ Cells } & \multirow[b]{2}{*}{$\mathrm{NGF}, \mathrm{pg} / \mathrm{mL}$} & \multicolumn{3}{|c|}{ FACS analyses, percentage of cells } \\
\hline & & $\mathrm{NGF}^{+}$ & TrkA $^{+}$ & p75 $5^{+}$ \\
\hline Unstimulated FLSs (meniscal injury $n=4$ ) & $30 \pm 5$ & $4.5 \pm 0.3$ & $1.33 \pm 0.4$ & $0.5 \pm 0.05$ \\
\hline FLSs + IL-1 $\beta$ (meniscal injury) & $110 \pm 28^{\mathrm{a}}$ & $12.4 \pm 2^{\mathrm{a}}$ & $16.5 \pm 5^{\mathrm{a}}$ & $0.4 \pm 0.2$ \\
\hline FLSs + TNF-a (meniscal injury) & $129 \pm 23^{\mathrm{a}}$ & $6.3 \pm 4^{\mathrm{a}}$ & $11.5 \pm 5^{\mathrm{a}}$ & $0.71 \pm 0.4$ \\
\hline FLSs from patients with PsA $(n=3)$ & $105 \pm 15^{\mathrm{a}}$ & $17 \pm 4^{\mathrm{a}}$ & $10 \pm 3^{\mathrm{a}}$ & $1.0 \pm 0.4$ \\
\hline FLSs from patients with RA $(n=4)$ & $65 \pm 4^{b}$ & $8 \pm 0.4^{b}$ & $5.5 \pm 0.4^{b}$ & $0.5 \pm 0.4$ \\
\hline FLSs from patients with OA $(n=4)$ & $34 \pm 2$ & $3.9 \pm 0.2$ & $0.9 \pm 0.2$ & $0.7 \pm 0.2$ \\
\hline
\end{tabular}

Third-passage fibroblast-like synoviocytes (FLSs) (5,000 cells in $200 \mu \mathrm{L}$ of Dulbecco's modified Eagle's medium [DMEM] complete medium) in 96 -well plates were cultured for 6 days. Unstimulated cells were cultured in DMEM only, and stimulated cells were cultured in DMEM with cytokines tumor necrosis factor-alpha (TNF-a) $(1 \mathrm{ng} / \mathrm{mL})$ and interleukin-1-beta (IL-1 $\beta)(1 \mathrm{ng} / \mathrm{mL})$. Data are expressed as mean \pm standard deviation. Nerve growth factor (NGF), TrkA, and p75 data of unstimulated FLSs were compared with NGF, TrkA, and p75 data of FLSs of other groups mentioned in the table. ${ }^{a / b}$ Significantly different from unstimulated cells ( $P$ P $<0.001$, ${ }^{b} P<0.05$ Student $t$ test). FACS, fluorescence-activated cell sorting; OA, osteoarthritis; PsA, psoriatic arthritis; RA, rheumatoid arthritis.

influence angiogenesis and cell trafficking [3]. In patients with RA or PsA, pannus tissue adheres to the surface of articular cartilage; proliferating FLSs produce proteinases that degrade cartilage and underlying cortical bone [4]. We noticed that proinflammatory cytokines upregulate NGF/TrkA in FLSs, NGF/TrkA is upregulated in FLSs of inflammatory arthritis (Table 1), and NGF is mitogenic to FLSs (Figure 1). These observations suggest an autocrine loop of NGF for FLS proliferation and suggest that dysregulated production of NGF has the potential to influence the inflammatory and proliferative cascades of PsA and RA.

\section{Abbreviations}

ELISA, enzyme-linked immunosorbent assay; FLS, fibroblast-like synoviocyte; $N G F$, nerve growth factor; NGF-R, nerve growth factor receptor; $O A$, osteoarthritis; PsA, psoriatic arthritis; RA, rheumatoid arthritis; SF, synovial fluid; SpA, spondyloarthritis; ST, synovial tissue.

\section{Competing interests}

The authors declare that they have no competing interests.
Published: 28 June 2010

\section{References}

1. Barthel C, Yeremenko N, Jacobs R, Schmidt RE, Bernateck M, Zeidler H, Tak PP, Baeten D, Rihl M: Nerve growth factor and receptor expression in rheumatoid arthritis and spondyloarthritis. Arthritis Res Ther 2009, 11:R82.

2. Raychaudhuri SP, Raychaudhuri SK: The regulatory role of nerve growth factor and its receptor system in fibroblast-like synovial cells. Scand J Rheumatol 2009, 38:207-215.

3. Raychaudhuri SK, Raychaudhuri SP, Weltman H, Farber EM: Effect of nerve growth factor on endothelial cell biology: proliferation and adherence molecule expression on human dermal microvascular endothelial cells. Arch Dermatol Res 2001, 293:291-295.

4. Wernicke D, Schulze-Westhoff C, Brauer R, Petrow P, Zacher J, Gay S, Gromnica-Ihle E: Stimulation of collagenase 3 expression in synovial fibroblasts of patients with rheumatoid arthritis by contact with a threedimensional collagen matrix or with normal cartilage when coimplanted in NOD/SCID mice. Arthritis Rheum 2002, 46:64-74.

\section{doi:10.1186/ar3030}

Cite this article as: Raychaudhuri SK, Raychaudhuri SP: Functional significance of nerve growth factor and its receptor (TrkA) in inflammatory arthritis. Arthritis Research \& Therapy 2010, 12:404. 